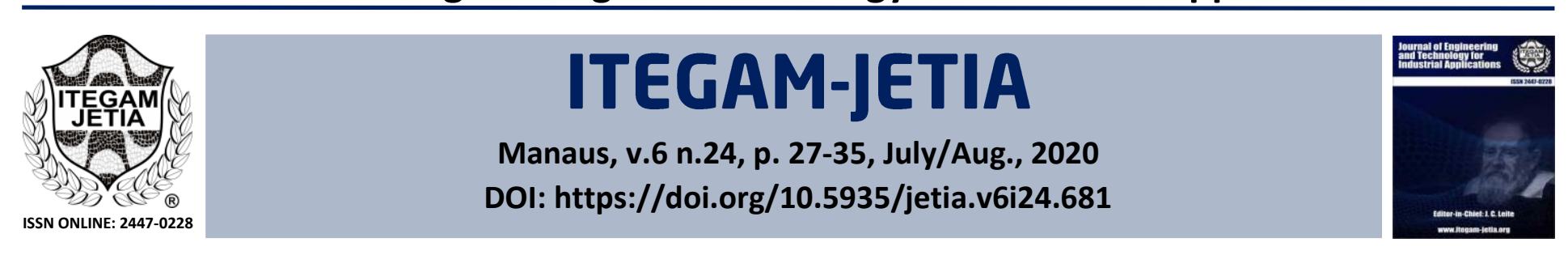

\title{
SYSTEMATIC MAPPING APPROACH TO SUPPORT ADMINISTRATION QUANTITATIVE RESEARCH
}

\section{Sanderson de Paula Barbosa ${ }^{1}$, Franklin da Silva Nonato ${ }^{2}$, André Luiz de Castro Leal ${ }^{3}$ and Márcio Zamboti Fortes*4}

1,2,3 Federal Rural University of Rio de Janeiro - UFRRJ. Seropédica-Rio de Janeiro, Brazil.

${ }^{4}$ Federal Fluminense University - UFF. Nitéroi-Rio de Janeiro, Brazil.

\begin{abstract}
${ }^{1}$ http://orcid.org/0000-0002-7143-4733 (i), ${ }^{2}$ http://orcid.org/0000-0002-8624-6575 ㄹ, ${ }^{3}$ http://orcid.org/0000-0002-8206-0992 (D), ${ }^{4}$ http://orcid.org/0000-0003-4040-8126 (i)
\end{abstract}

Email:*mzamboti@id.uff.br

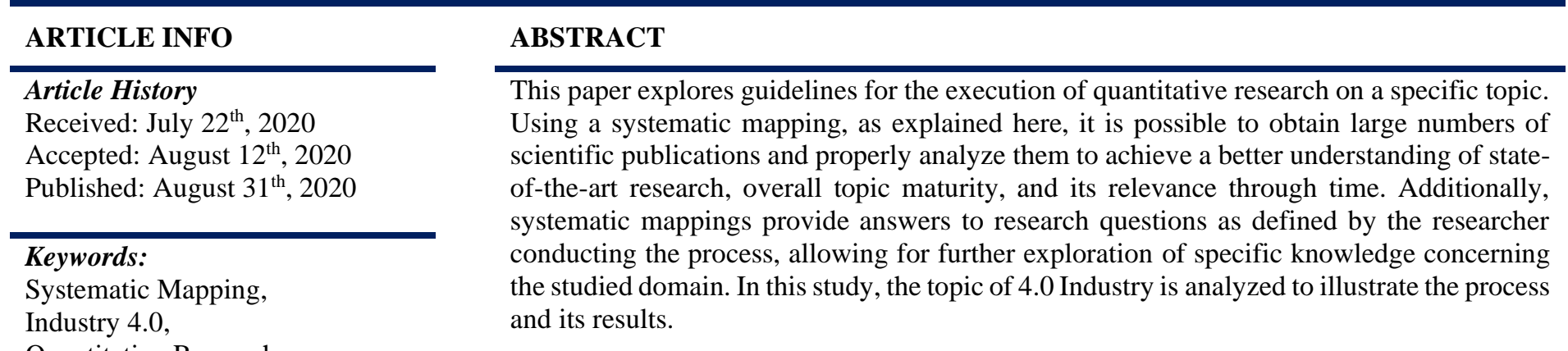

Quantitative Research,

Tutorial Article.

Copyright (C2016 by authors and Galileo Institute of Technology and Education of the Amazon (ITEGAM). This work is licensed under the Creative Commons Attribution International License (CC BY 4.0).

\section{INTRODUCTION}

The guidelines compose a systematic mapping method. It is a method of building a classification scheme and structuring a field of interest and for structuring a broad research field concerning research questions about contents, methods, and trends in the available publications. The analysis of results focuses on frequencies of publications for categories within the scheme; thereby, the coverage of the research field can be determined. There are distinctions between mapping studies and conventional systematic literature review (SLR) [1]. The mapping studies provide a more detailed review of the topics covered in each primary study including issues such as major outcomes and quality evaluations of primary studies [2].

We intend to demonstrate the guidelines for this technique by using it to find and classify the scientific works, in this applied in 4.0 Industry [3]. It is important to identify the available literature, authors, period, type of model, applications to understand the universe of research about this domain and the state of the art. The strategy consists to specify questions, data extraction in the digital data sources (libraries), automatic searches, analysis, categorizations, tabulations, plot graphs and to demonstrate explicitly the method used thus setting a systematic mapping.

The present study will be presented in sections like Section 2 , related words; section 3 , systematic mapping process; section 4 , results from presentation; section 5 , conclusions.

\section{RELATED WORKS}

It is possible to find in the literature several papers about systematic mapping writing by authors from different areas of knowledge.

The authors [4] investigated research related to established service level agreements to ensure quality control of services provided by cloud servers to consumers and businesses. They have developed a systematic study and mapping of how SLAs are being managed. Thus, 328 surveys were studied and classified into seven technical categories. In this way, it was possible to map the types of research, their contributions, and demographic information from these studies. Thus, the authors identified not only the SLA 
management models but the gaps in the studies of this administrative tool.

For [5] discuss several guidelines and empirical studies that can be used to improve the quality of ongoing research and they discuss the likelihood that we can use meta-analysis to combine the results of related studies. The authors propose a specific guideline, based on your experience in software engineering with backgrounds in statistics as well as computer science, and relate the problems with standard statistical procedures in software experiments. They propose to show a guideline to assist administration researchers to avoid major pitfalls in their research activities and to report their research correctly.

According [6] studied eighty studies on business process variability, which is the phenomenon known as the changes in the business processes of companies that occur due to the dynamic environment in which they operate. With the systematic mapping carried out, a conceptual synthesis on the subject was established, in addition to establishing opportunities for future research. They researched what are the main characteristics of process variation, the approaches that are available, and what are the current challenges in managing process variations in the business world.

For [2] suggested that software engineers and empirical software engineering researchers should adopt the evidence-based practice as pioneered in the fields of medicine and sociology. In this paper, the author explores the aspects of software engineering in several scientific publications considering a string associating software engineering and other terms as a review of studies, structured review, systematic review, literature review, literature analysis, and others. With this, the authors consider the relationships between systematic literature review topics and the software engineering undergraduate curriculum.

According [7] develop a systematic mapping of the software engineering field. The results were focused on frequencies of publications for categories. The objective of the authors was to demonstrate conduct to make a systematic mapping study in software engineering. In the work, the authors discuss the difference in the goals, breath, validity issues, and implications between systematic mapping and reviews.

\section{THE SYSTEMATIC MAPPING PROCESS}

\section{III.1 MAIN PROCESS}

The method to apply systematic mapping was done in steps. Figure 1 shows the step by step of the systematic mapping process. It is the main process (in macro vision). To describe the process, we will use a Structured Analysis and Design Technique (SADT) model [8] (Figure 1), where the following activities are mentioned: Step 1: Prepare Contextualization; Step 2: Preliminary filtering; Step 3: Full filter; Step 4: Classify results. These activities represent the context diagram (A0).

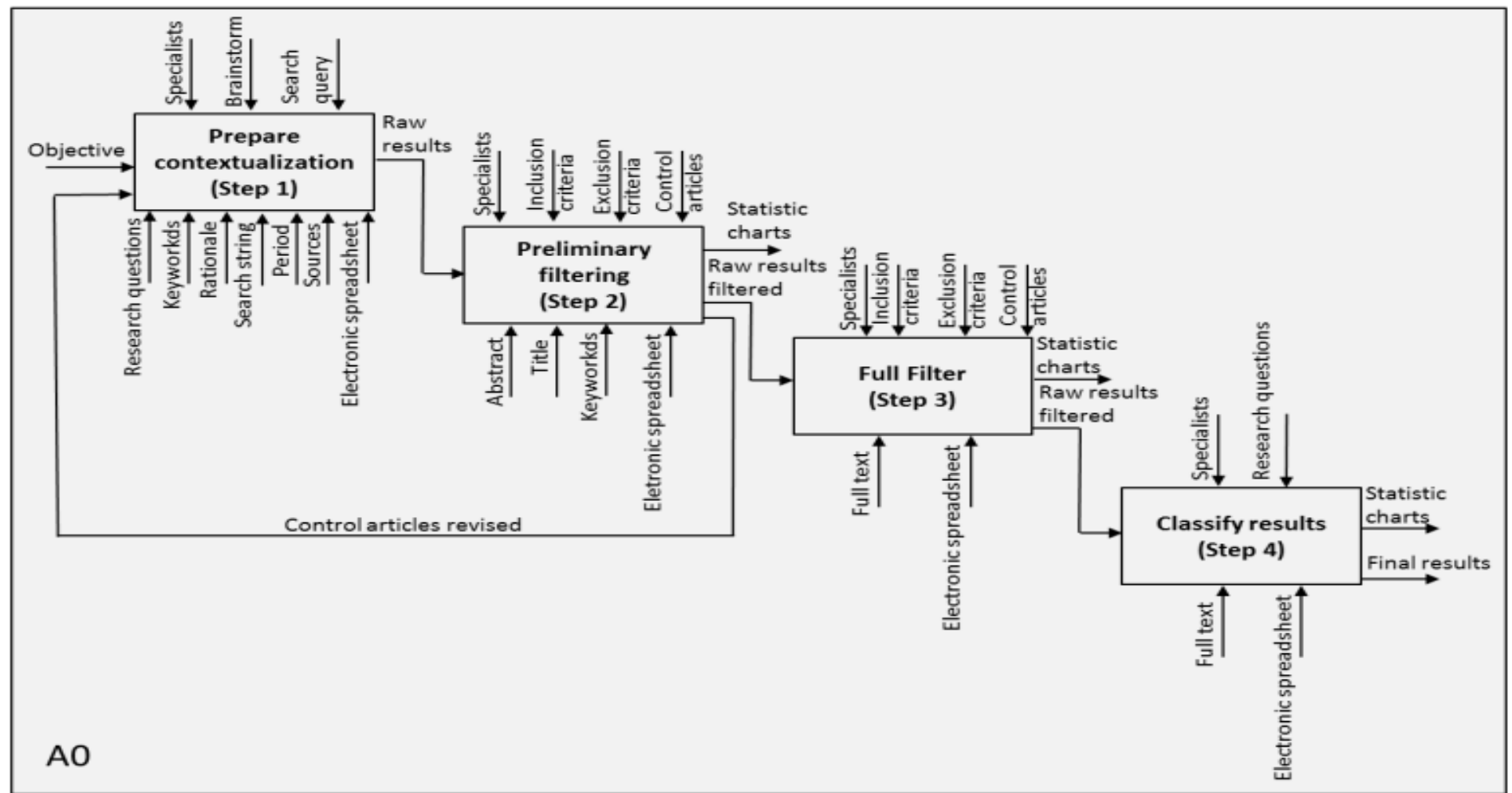

Source: Authors, (2020).

The SADT structure contains an arrow pointing into the left side of a box represents things that will be transformed by the box, these represent inputs. An arrow pointing down into the top of the box represents the control that affects how the box transforms the things entering from the left side. Arrows entering the bottom of a box represent mechanism and provide the analyst with the ability to document how the function will operate, who will perform it, or what physical resources are needed to perform the function. Text labels to describe boxes and arrows and text to define the precise meanings of diagram elements.

For each step was done a set of activities will be described below.

\section{III.2 PREPARE CONTEXTUALIZATION (STEP 1)}

The first effort was reuniting the group of specialists and discuss together, in a brainstorming strategy, what and how 
elements could help achieve the objective. The specialists were formed by three researchers on the field of information systems and technology.

According to the first step (Step 1) of the context diagram, many elements were defined. It was defined as structural elements and contents.

The first structure element defined was Objective. This represents the principal goal of the research. It was defined as 'To know state-of-the-art research on 4.0 Industry'.

The definition of the objective and other structures was established in the first activity of the main systematic mapping process. Figure 2 shows that the process is composed of two activities. In the first (1.1), the specialists configure the structures that will use in filters and, in the second (1.2), they execute a query to filter the preliminary results.

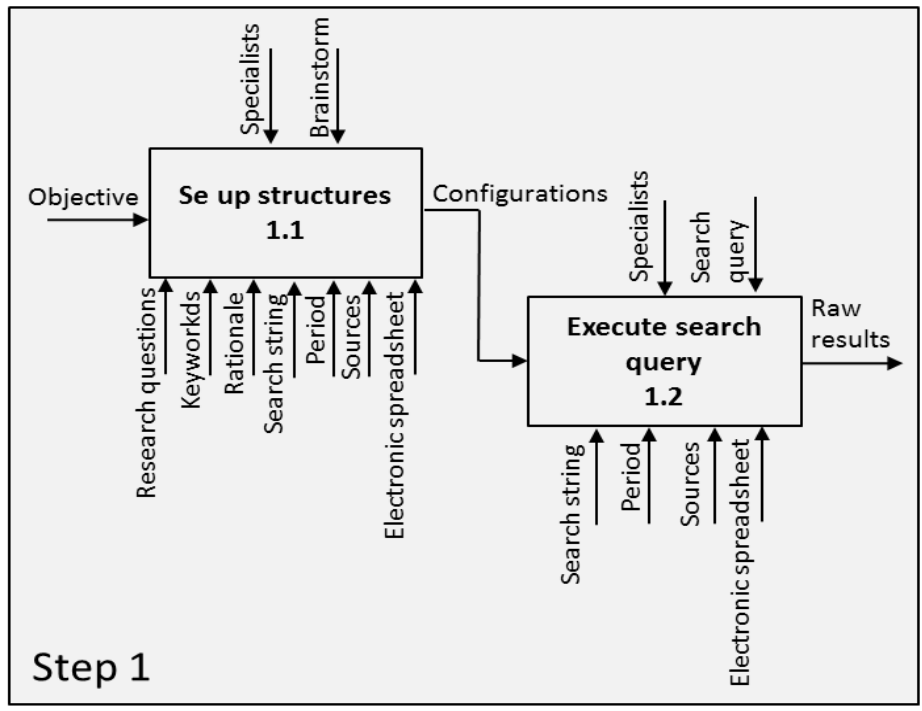

Figure 2: SADT of the systematic mapping process.

Source: Authors, (2020).

The structures and contents were defined as presents bellow and are results of 1.1 Set up structures:

i) Research questions (mechanism):

The specialists formulate research questions as guidelines to analyze and to rank the articles. Answering these research questions (RQs) is the main purpose of the systematic mapping, thus, they must be elaborated in such a way as to provide an overview of the subject matter and any specific information that the study seeks to uncover.

Common examples of research questions are 'When have the studies been published?' allowing the mapping to uncover the progress of publication quantity through time; or 'Where have the studies been published?' which helps to understand the maturity of said research, considering which venues (journals, conferences, etc.) have hosted these publications. More specific RQs are also used, to uncover more valuable information on the subject.

ii) Search Strings (mechanism):

The strings are used to search the web in some source (discussed below). They are defined in two times. The first list of terms with:

$\mathrm{P}=$ ('Industrial Management and Control 4.0')
$\mathrm{Q}=$ ('monitoring' OR ‘control' OR 'application' OR 'analysis' OR 'structure' OR 'steel industry' OR 'siderurgy' OR 'method')

$\mathrm{R}=$ ('industry 4.0' OR '4th industrial revolution' OR 'industrial 4.0')

Search String $=\mathrm{P}^{\wedge}(\mathrm{Q} v \mathrm{R})$

In the final, the search string was defined as:

(Industrial Management and Control 4.0) AND ('monitoring' OR 'control' OR 'application' OR 'analysis' OR 'structure' OR ‘steel industry' OR 'siderurgy' OR 'method') OR ( 'industry 4.0 ' OR ' 4 th industrial revolution' $\mathrm{OR}$ 'industrial $\left.4.0^{\prime}\right)$.

iii) Source (mechanism):

The search string was used in searches into some sources in the scientific libraries. The sources selected to the search were:

-SpringerLink, Web of Science ('https://link.springer.com/');

-Engineering Village

('https:/www.engineeringvillage.com/');

- Scopus ('https://www.scopus.com/').

However, this work was used just the that are below

- ACM Digital Library ('https://dl.acm.org/');

-IEEE Xplore

('https://ieeexplore.ieee.org/Xplore/home.jsp');

- Science Direct ('https://www.sciencedirect.com/').

The intention is to catch studies on conferences and journals in the specific domain.

iv) Period (mechanism):

The search was done in a period of 'initial year' and 'final year', eg. 2000 to 2019 .

v) Area (mechanism):

The searches were done in the Administration area.

vi) Inclusion Criteria (IC) (mechanism):

The publication presents information on some kind of 4.0 Industry management and control (for any reason) (IC1). It was used as a first filter and to explain the guideline.

vii) Exclusion Criteria (EC) (mechanism):

The specialists established some exclusion criteria. These were used to dispose of articles. The established criteria were:

- It does not provide an abstract (EC1).

- It is just an abstract (EC2).

- It is not written in English (EC3).

- It is a copy or an older version of another publication that has already been considered (EC4).

- It is not a primary study (e.g., editorials, summaries of keynotes, tutorials, etc.) (EC5).

- It is not possible to have access to the full version of the publication (EC6).

viii) Control Articles (CA) (mechanism): 
Control Articles (CAs) are manually selected publications concerning the subject meant to be amongst the results yielded by the RQs. When possible, these may be well-known publications, as they are meant to provide a baseline on the type of article the study is meant to cover.

For this guide, on the subject of 4.0 Industry, the CA selection was as follows.

For this guide, on the subject of 4.0 Industry, the CA selection was as follows: Smart Factory of Industry 4.0: Key Technologies, Application Case, and Challenges [9], When Time Matters: Predictive Mission Planning in Cyber-Physical Scenarios [10], Big Data-Oriented Product Infant Failure Intelligent Root Cause Identification Using Associated Tree and Fuzzy DEA [11], Development of an instrument for the assessment of scenarios of work 4.0 based on socio-technical criteria [12], An ontology-based framework for the management of machining information in a data mining perspective [13], Complex System Health Management Based On Condition Monitoring And Test Data [14], Simulation-based dynamic shop floor scheduling for a flexible manufacturing system in the industry 4.0 environment [15].

\section{ix) Structure (mechanism):}

After structure elements and their respective contents were configured, the specialists elaborate the electronic spreadsheet. The spreadsheet helps to organize the results and accounts for them. The organization of the first elements was organized in rows in columns as presented below. These elements serve as input to the search query (output of Step 1 - Prepare contextualization).

Table 1: Electronic spreadsheet with configuration elements.

\begin{tabular}{|c|c|c|}
\hline Objective: & $\begin{array}{c}\text { To know state-of-the-art research on } 4.0 \\
\text { Industry }\end{array}$ & \\
\hline $\begin{array}{l}\text { Research } \\
\text { Questions }\end{array}$ & Rationale & \\
\hline RQ1 & $\begin{array}{l}\text { When was it published? What is the } \\
\text { research period? }\end{array}$ & \multirow{6}{*}{$\begin{array}{c}\text { To } \\
\text { explain } \\
\text { more } \\
\text { details } \\
\text { about } \\
\text { such } \\
\text { research } \\
\text { questions }\end{array}$} \\
\hline RQ2 & $\begin{array}{l}\text { Where is the subject being published more } \\
\text { frequently? }\end{array}$ & \\
\hline RQ3 & $\begin{array}{c}\text { What is the approach of research on } \\
\text { production line control systems, in the } \\
\text { Brazilian steel industry, within the strategy } \\
\text { of industry } 4.0 \text { ? }\end{array}$ & \\
\hline RQ4 & $\begin{array}{l}\text { How are steel companies being structured } \\
\text { about production line control departments? }\end{array}$ & \\
\hline RQ5 & $\begin{array}{l}\text { How is the Brazilian steel industry working } \\
\text { with industry } 4.0 \text { about condition control of } \\
\text { production lines? }\end{array}$ & \\
\hline RQ6 & $\begin{array}{l}\text { What is being researched / studied about } \\
\text { industry } 4.0 \text { correlated with theories of } \\
\text { strategic management of industrial } \\
\text { production? }\end{array}$ & \\
\hline
\end{tabular}

Source: [3].

Search String: see ii) Search Strings (mechanism) section.

Period: see iv) Period (mechanism) section.

Area: see v) Area (mechanism) section.

Sources: see iii) Source (mechanism) section.

\section{Inclusion Criteria}

IC1 - The publication concerns the subject of... ((vi) Inclusion Criteria (IC) (mechanism)).

\section{Exclusion Criteria}

see vii) Exclusion Criteria (EC) (mechanism) section.

\section{Control Articles}

CA1, CA2, CA3, CA4, CA5, CA6, CA7. see viii) Control Articles (CA) (mechanism) section.

After the initial configurations prepared, it is possible to execute the search query (1.2 Execute search query).

\section{x) Raw Results (output):}

The raw results were the first results achieved after the execution search query through the mechanisms and controls.

The results were listed in the sheet as presents in the example of Table 2 (partial vision). In this sheet, we list all publications returned by the search query in all sources, without eliminating duplicates (same publication returned by different sources - see iii) Source (mechanism) section). Publications should be sorted by source. Publications present in multiple sources should appear in the list of each source.

Table 2: Electronic spreadsheet with raw results model [3].

\begin{tabular}{|c|c|c|c|}
\hline Article & Source & Year & Title \\
\hline [16] & ScienceDirect & 2017 & $\begin{array}{l}\text { Research on Big Data - A systematic } \\
\text { mapping study }\end{array}$ \\
\hline [9] & in IEEE Access & 2018 & $\begin{array}{l}\text { Smart Factory of Industry 4.0: Key } \\
\text { Technologies, Application Case, and } \\
\text { Challenges }\end{array}$ \\
\hline [10] & in IEEE Access & 2019 & $\begin{array}{l}\text { When Time Matters: Predictive } \\
\text { Mission Planning in Cyber-Physical } \\
\text { Scenarios }\end{array}$ \\
\hline [17] & in IEEE Access & 2018 & $\begin{array}{l}\text { A Cloud-Based System for } \\
\text { Improving Retention Marketing } \\
\text { Loyalty Programs in Industry 4.0: A } \\
\text { Study on Big Data Storage } \\
\text { Implications }\end{array}$ \\
\hline [11] & in IEEE Access & 2019 & $\begin{array}{l}\text { Big Data-Oriented Product Infant } \\
\text { Failure Intelligent Root Cause } \\
\text { Identification Using Associated Tree } \\
\text { and Fuzzy DEA }\end{array}$ \\
\hline [18] & in IEEE Access & 2018 & $\begin{array}{l}\text { Practical Guide to Smart Factory } \\
\text { Transition Using IoT, Big Data and } \\
\text { Edge Analytics }\end{array}$ \\
\hline [12] & $\begin{array}{l}\text { ACM Digital } \\
\text { Library }\end{array}$ & 2018 & $\begin{array}{l}\text { Development of an instrument for the } \\
\text { assessment of scenarios of work } 4.0 \\
\text { based on socio-technical criteria }\end{array}$ \\
\hline [19] & in IEEE Access & 2018 & $\begin{array}{l}\text { Exploiting Industrial Big Data } \\
\text { Strategy for Load Balancing in } \\
\text { Industrial Wireless Mobile Networks }\end{array}$ \\
\hline [20] & in IEEE Access & 2019 & $\begin{array}{l}\text { IEEE Access } \\
\text { Special Section } \\
\text { Editorial: Key Technologies for } \\
\text { Smart Factory of Industry } 4.0\end{array}$ \\
\hline [21] & $\begin{array}{l}\text { ACM Digital } \\
\text { Library }\end{array}$ & 2019 & $\begin{array}{l}\text { Data Analytics and BI Framework } \\
\text { based on Collective Intelligence and } \\
\text { the Industry } 4.0\end{array}$ \\
\hline [13] & ScienceDirect & 2018 & $\begin{array}{l}\text { An ontology-based framework for the } \\
\text { management of machining } \\
\text { information in a data mining } \\
\text { perspective }\end{array}$ \\
\hline [14] & in IEEE Access & 2018 & $\begin{array}{l}\text { IEEE Access Special Section } \\
\text { Editorial: Complex System Health } \\
\text { Management Based On Condition } \\
\text { Monitoring And Test Data }\end{array}$ \\
\hline [22] & in IEEE Access & 2017 & $\begin{array}{l}\text { Industrial Big Data Analysis in Smart } \\
\text { Factory: Current Status and Research } \\
\text { Strategies }\end{array}$ \\
\hline [23] & in IEEE Access & 2018 & $\begin{array}{l}\text { Industrial Big Data Analytics for } \\
\text { Prediction of Remaining Useful Life } \\
\text { Based on Deep Learning }\end{array}$ \\
\hline [15] & in IEEE Access & 2017 & $\begin{array}{l}\text { Simulation-based dynamic shop floor } \\
\text { scheduling for a flexible } \\
\text { manufacturing system in the industry } \\
4.0 \text { environment }\end{array}$ \\
\hline
\end{tabular}

Source: Authors, (2020). 


\section{III.3 PRELIMINARY FILTERING (STEP 2)}

In the preliminary filtering, the specialists execute two activities. They filter the publications and classify them. Figure 3 shows these two activities.

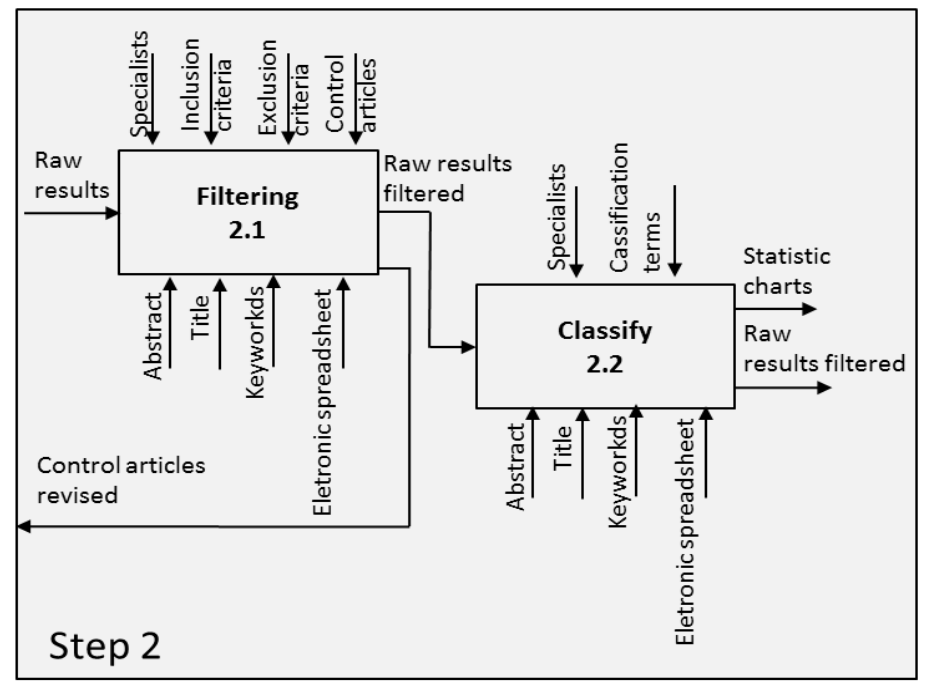

Figure 3: First filter and classification.

Source: Authors, (2020).

The Filtering (2.1) activity has as a first aim the unification of publications present in multiple sources. After this, the results list got 921 occurrences of distinct publications.

After unifying publications, each publication should be analyzed against the selection criteria (ICs and ECs) considering Title, Abstract, and Keywords only. When the analysis indicates the item satisfies all inclusion criteria, the analysis should read 'OK'. In case it points to the exclusion of the item, you should indicate if the publication doesn't satisfy an inclusion criterion (e.g., IC1) or if it satisfies an exclusion criterion (e.g., EC5). The $\mathrm{ECs}$ are more than one, the identification criteria are marked with EC1, EC2, EC3, EC4, EC5, and EC6.

Through analysis of title, abstract, and keywords, publications that did not meet all inclusion criteria or met any of the exclusion criteria have been removed. Among the occurrences were found in the CAs.

The Classify activity (2.2) identifies publications according to a categorization. In addition to the answers given RQs, these were complemented by categorizations. To the RQ6 was detached the year of the publication and de venue, this last categorized by the acronym of the event name. This information, standardized, is important to plot graphs. But, for RQ7, there was a concern to focus on relevant information on the quality and maturity of publications and communities in which they were found. We suggest three categories have been proposed to analyze the relevance: Venue Type (after reading found the types Journal, Chapter, Conference, Symposium, and Workshop), Impact Factor, and Scholar Citation, but to exemplify here, we used venue type.

\section{III.4 FULL FILTER (STEP 3)}

In this step, each publication should be analyzed against the selection criteria (ICs and ECs) considering its full text. The Analysis column works exactly like the one in the previous step (1st filter, eg., OK, IC and EC). Figure 4 shows the activity (unique) for each of these steps.

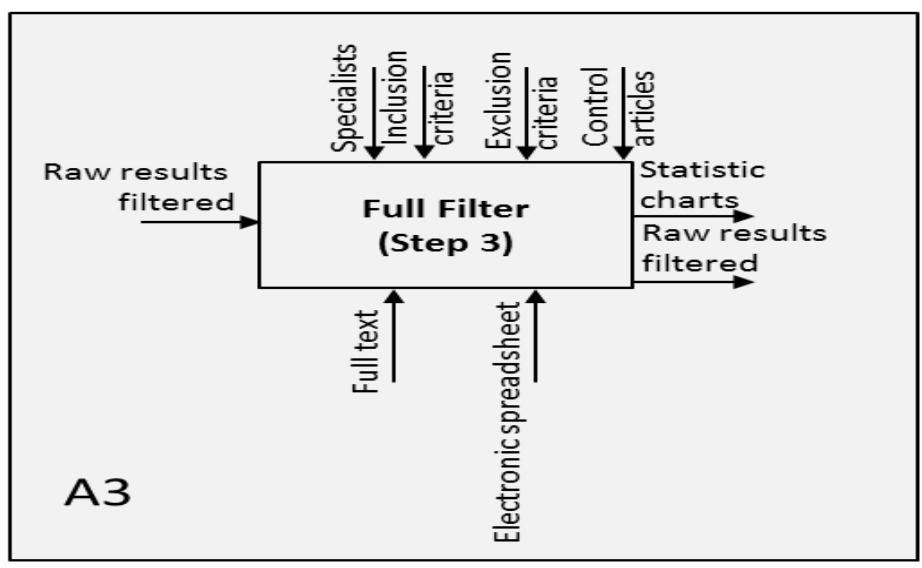

Figure 4: Filter in the full papers.

Source: Authors, (2020).

We can consider a study with 144 occurrences as final results according to the initial criteria and the resume of the evolution of realized filters can be seen in Table 3 . The sequence of activities is duplicated removal, to found the CAs and verification of IC and ECs criteria.

Table 3. Results from the selection stages.

\begin{tabular}{|c|c|c|c|c|}
\hline $\begin{array}{c}\text { Applied } \\
\text { Criteria }\end{array}$ & $\begin{array}{c}\text { Analyzed } \\
\text { Content }\end{array}$ & $\begin{array}{c}\text { Initial } \\
\text { Occurrences }\end{array}$ & $\begin{array}{c}\text { Final } \\
\text { Results }\end{array}$ & $\begin{array}{c}\text { Reduction } \\
(\%)\end{array}$ \\
\hline $\begin{array}{c}\text { Duplicated } \\
\text { Removal }\end{array}$ & $\begin{array}{c}\text { Title, abstract } \\
\text { and keywords }\end{array}$ & 1595 & 921 & 42,26 \\
\hline CAs & $\begin{array}{c}\text { Title, abstract } \\
\text { and keywords }\end{array}$ & 7 & 7 & 0 \\
\hline $\begin{array}{l}\text { IC and ECs } \\
(1,2,3,4,5,6)\end{array}$ & $\begin{array}{c}\text { Title, abstract } \\
\text { and keywords }\end{array}$ & 921 & 206 & 77,63 \\
\hline $\begin{array}{l}\text { IC and ECS } \\
(1,2,3,4,5,6)\end{array}$ & Full text & 206 & 144 & 30,10 \\
\hline Final Result & - & 1595 & 144 & 90,97 \\
\hline
\end{tabular}

Source: [3].

\section{III.5 CLASSIFY RESULTS (STEP 4)}

While reading the full text, the specialist should try to answer and review all RQs. But particularity for this activity, the specialists are also concerned at the categorization of questions and the focus given to the RQ1 and RQ3.

Figure 5 presents the input, control, mechanism, and output of the classifying results process.

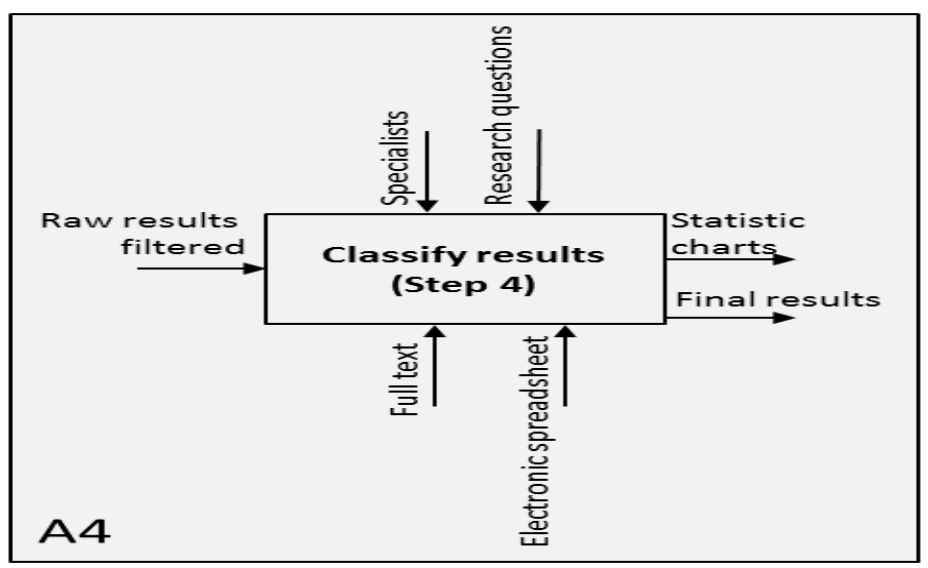

Figure 5: Using Research Questions. Source: Authors, (2020). 


\section{RESULTS}

It is important to realize that as output results of the activities of the systematic mapping process were generated numeric graphics, but the results of systematic mapping will be presented from two perspectives: from numerical graphs of the column data and qualitative analysis of the texts captured and described in the columns for research questions. The results were made on the final occurrences and it presents for each research question in the sections below. Figures 6 to 11 show examples of these results demonstration. Tables 4 and 5 are a summary of these data.

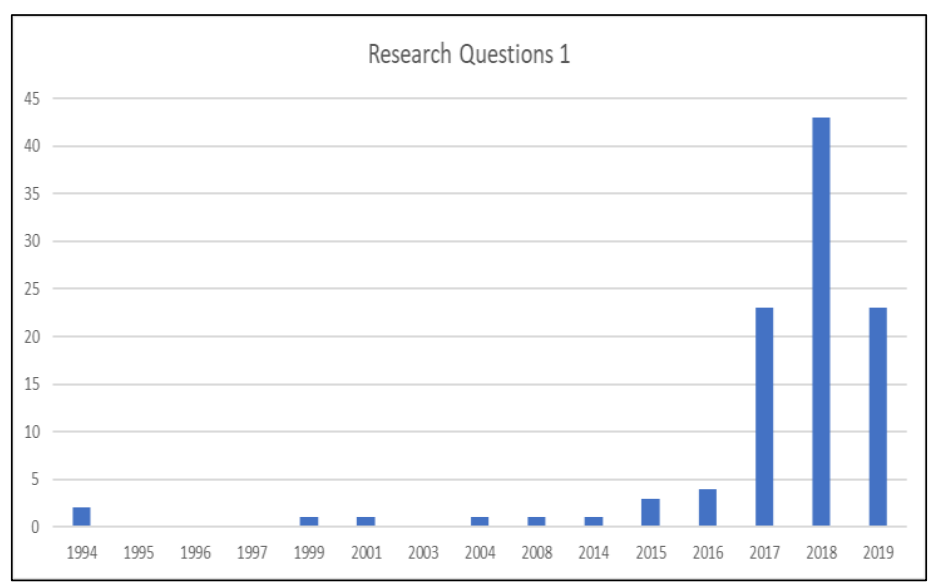

Figure 6: Distribution of publications per year. Source: [3].
All papers acquired and quantified on the raw results section are initially assigned IDs, which are used to identify such papers in the tables and Appendix. During the filtering process, however, many of these are removed due to not being part of the studied topic. Because of that, IDs are not always numbered in an appropriate sequence but instead leap from number to number to account for removed paper IDs. As such, despite having IDs up to [15], this does not reflect that ninety-six papers were considered in the study.

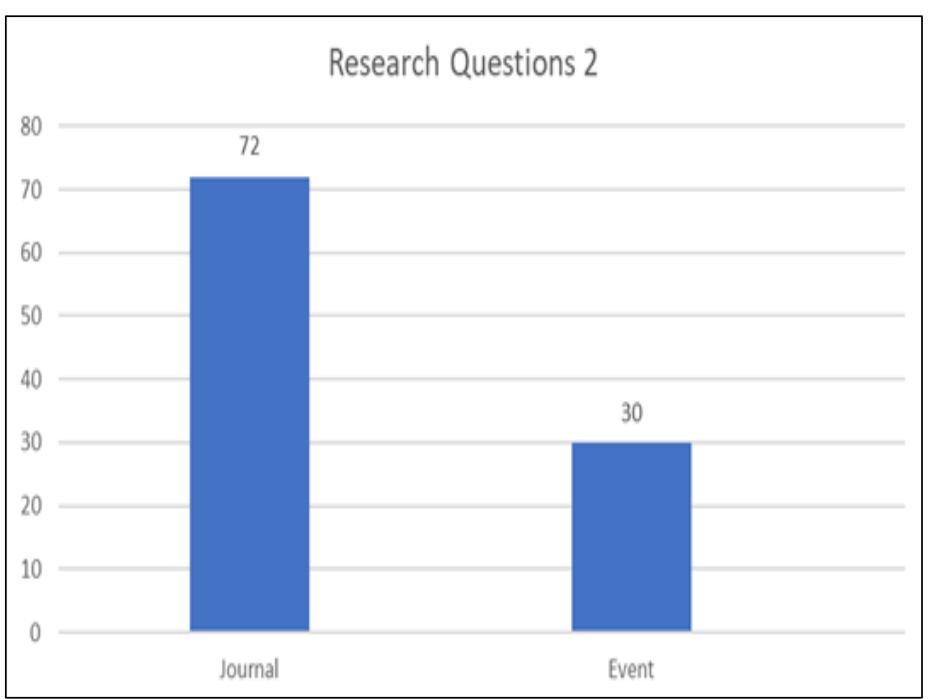

Figure 7: Distribution of publications per venue type. Source: [3].

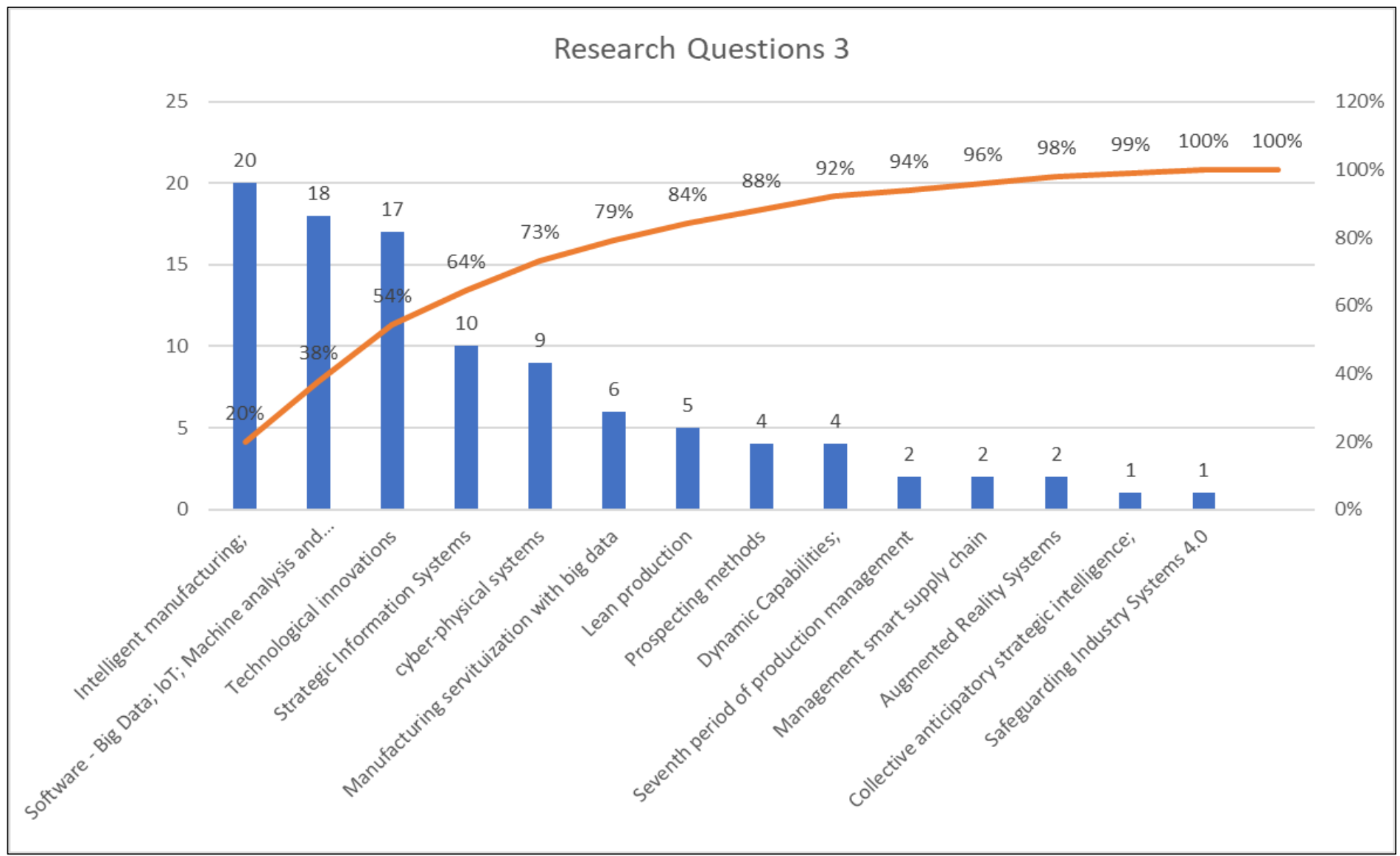

Figure 8: What is the approach of research on production line control systems, in the Brazilian steel industry, within the strategy of industry 4.0 ?

Source: [3]. 


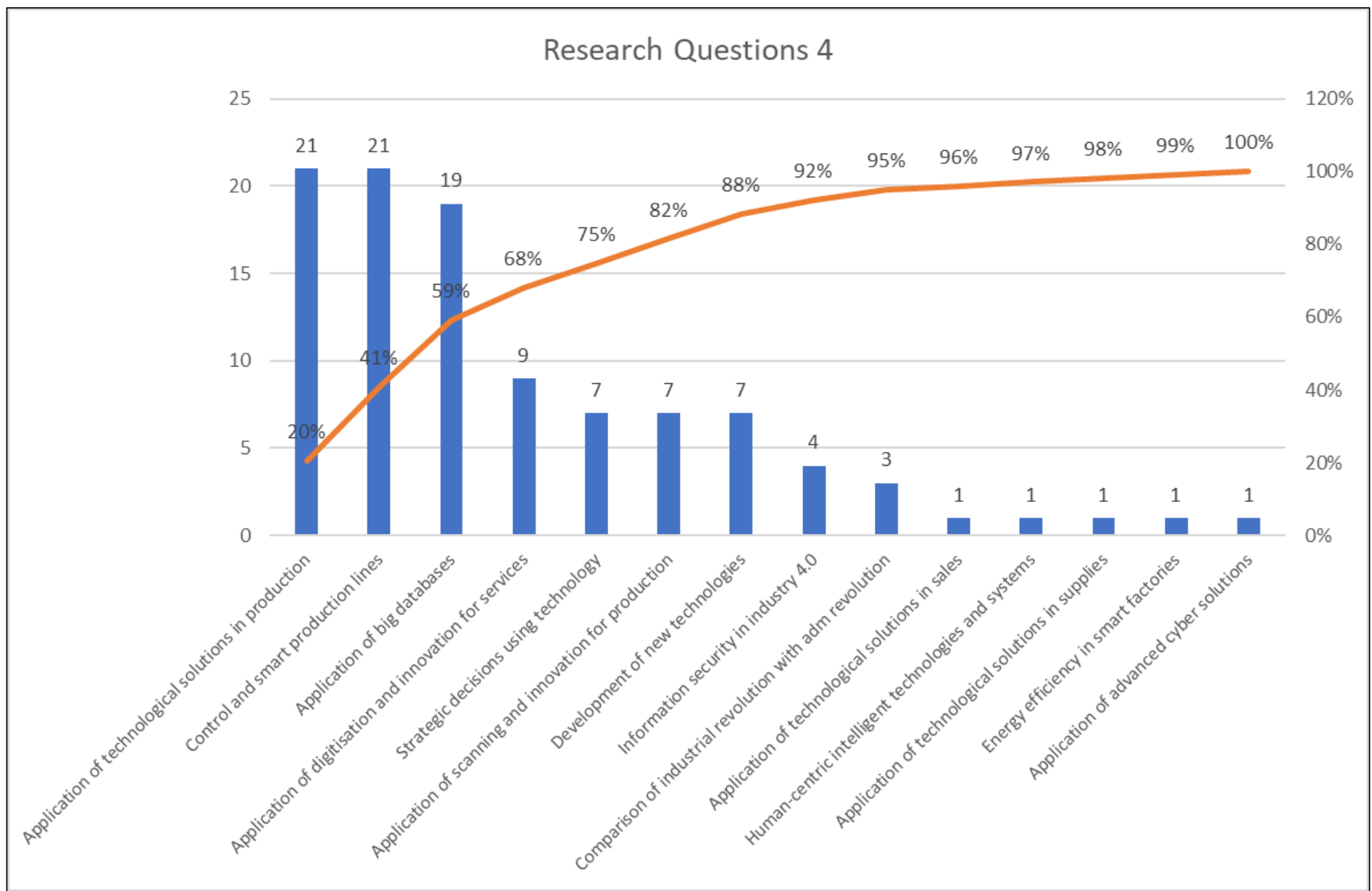

Figure 9: How are steel companies being structured about production line control departments? Source: [3].

Table 4: Categories of the second research question.

\begin{tabular}{|c|c|c|}
\hline Category & Description & Number of articles \\
\hline Journal & Article published in scientific journals. & {$[16],[9],[17],[11],[18],[19],[20],[13],[14],[22]$ and $[23]$.} \\
\hline Event & Article published in congresses and seminars. & {$[12],[21]$, and [15]. } \\
\hline
\end{tabular}
Source: [3].

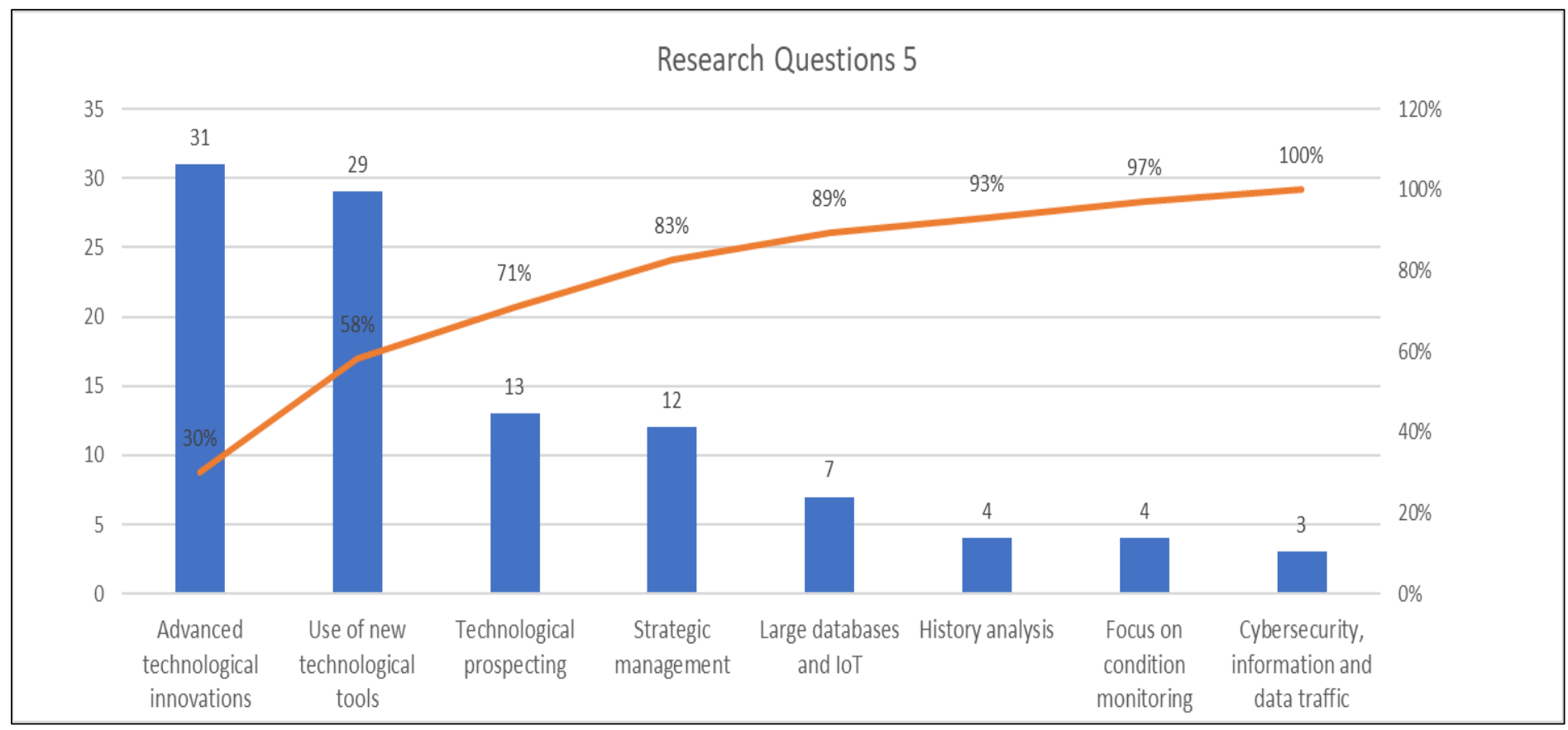

Figure 10: How is the Brazilian steel industry working with industry 4.0 about condition control of production lines? Source: [3]. 


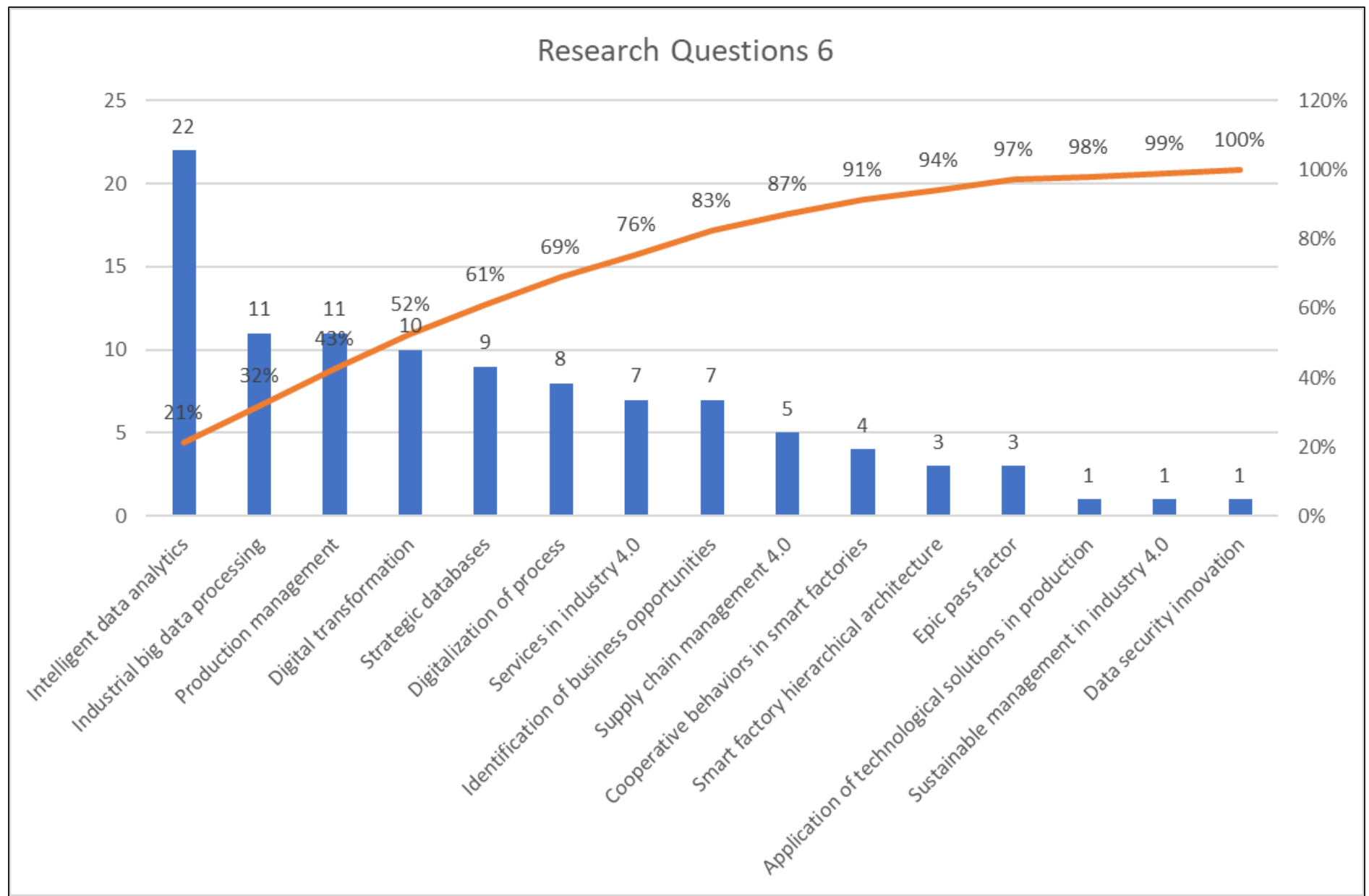

Figure 11: What is being researched / studied about industry 4.0 correlated with theories of strategic management of industrial production?

Source: [3].

Table 5: Categories of the fifth research question.

\begin{tabular}{|c|c|c|}
\hline Category & Description & Number of articles \\
\hline $\begin{array}{c}\text { Advanced } \\
\text { technological } \\
\text { innovations }\end{array}$ & $\begin{array}{c}\text { Development of advanced } \\
\text { technologies. }\end{array}$ & $\begin{array}{c}{[16],[17],[11],[18],} \\
{[12],[19],[21],[13],} \\
{[22], \text { and [23]. }}\end{array}$ \\
\hline $\begin{array}{c}\text { Technological } \\
\text { prospecting }\end{array}$ & $\begin{array}{c}\text { Development of new } \\
\text { businesses using technology. }\end{array}$ & {$[9]$ and [20]. } \\
\hline $\begin{array}{c}\text { Cyber security, } \\
\text { information, and } \\
\text { data traffic }\end{array}$ & $\begin{array}{c}\text { Focus on cyber-physical } \\
\text { systems and data security } \\
\text { management. }\end{array}$ & {$[14]$ and [15]. } \\
\hline
\end{tabular}

Source: [3].

It is important to describe a quantitative and qualitative analysis for each exposed graph. The discussions made by the researchers for each graphic help the readers to understand not only the static portrait exposed in the graphic but also the perception of the researchers about the investigated.

The categories presented in each graph are listed by the researchers according to the course of the study, that is, as they find the occurrence, the researchers quantify and analyze the groupings found. The groupings of the groupings and the scale of occurrences help in answering the research questions initially formulated. The understanding of the investigated domain arises as the researcher finds the answers, the number of occurrences, the groupings. Thus, by analyzing an isolated graph or analyzing the situation of one or more graphs, it is possible to understand the domain and problem investigated. The organized structure of the research based on steps and technical criteria used in an orchestrated way make up the systematic mapping.

\section{CONCLUSIONS}

The present work had as objective to present a practical guide on the scientific method of systematic mapping to support researchers in the field of administration in their studies on the state of the art of their research domain and to find answers for research questions that could provide us with a panorama of this area. The work presented the step by step of how to elaborate a systematic mapping and the results presented here are part of more consistent and comprehensive research on 4.0 Industry. Thus, they were explained succinctly only as examples of applying results from a systematic mapping. As already mentioned, the researchers need, for each graph, to establish discussions about their perceptions of the graph presented and the influence of the results in the investigated domain.

\section{REFERENCES}

[1] Kitchenham, B.; Charters, S.. Guidelines for performing Systematic Literature Reviews in Software Engineering (Version 2.3) - EBSE Technical Report. EBSE2007-0, 2007.

[2] Kitchenham B. A.; Pretorius R.; Budgen D.; Pearl Brereton O.; Turner M.; Niazi M.; Linkman S.. Systematic literature reviews in software engineering - A tertiary study. Inf. Softw. Technol., vol. 52, no. 8, pp. 792-805, 2010. doi: 10.1016/j.infsof.2010.03.006.

[3] Nonato, F. S.; Leal, A. L. C.; Fortes, M. Z.. Indústria 4.0 no Monitoramento e Controle da Produção: Um Estudo por Mapeamento Sistemático. Gestão em foco - UNISEPE, pp. 127-161, 2020. 
[4] Mubeen, S.; Asadollah, S. A.; Papadopoulos, A. V.; Ashjaei, M.; PeiBreivold, H.; Behnam, M.. Management of service level agreements for cloud services in IoT: A systematic mapping study. IEEE Access, 6, 30184-30207, 2017. doi: 10.1109/ACCESS.2017.2744677.

[5] Kitchenham B. A.; Pfleeger S. L.; Pickard L. M.; Jones P. W.; Hoaglin D. C.; El Emam K.; Rosenberg J.. Preliminary guidelines for empirical research in software engineering, IEEE Trans. Softw. Eng., vol. 28, no. 8, pp. 721-734, 2002. doi: 10.1109/TSE.2002.1027796.

[6] Valença, G.; Alves, C.; Alves, V.; Niu, N.. A systematic mapping study on business process variability. International Journal of Computer Science \& Information Technology, vol.5, no.1, 2013. doi: 10.5121/ijcsit.2013.5101.

[7] Petersen K.; Feldt R.; Mujtaba S.; Mattsson M.. Systematic Mapping Studies in Software Engineering, in Proc. of the 12th international conference on Evaluation and Assessment in Software Engineering, 2008, pp. 68-77, 2008.

[8] Ross D.; Schoman A.. Structured analysis for requirements definition. IEEE Trans Software Engineering, vol.3, no.1, pp.6-15, 1977. doi: 10.1109/TSE.1977.229899.

[9] Chen, B.; Wan, J., Shu, L.; Li, P.; Mukherjee, M.; Yin, B.. Smart factory of industry 4.0: Key technologies, application case, and challenges. IEEE Access, 6, 6505-6519, 2017. DOI: 10.1109/ACCESS.2017.2783682.

[10] Gaggero, M.; Di Paola, D.; Petitti, A.; Caviglione, L. When Time Matters: Predictive Mission Planning in Cyber-Physical Scenarios. IEEE Access, 7, 11246-11257, 2019. DOI: 10.1109/ACCESS.2019.2892310.

[11] He, Z.; He, Y.; Liu, F.; Zhao, Y.. Big data-oriented product infant failure intelligent root cause identification using associated tree and fuzzy DEA. IEEE Access, 7, 34687-34698, 2019. DOI: 10.1109/ACCESS.2019.2904759.

[12] Jenderny, S.; Foullois, M.; Kato-Beiderwieden, A. L.; Bansmann, M.; Wöste, L.; Lamß, J.; Röcker, C.. Development of an instrument for the assessment of scenarios of work 4.0 based on socio-technical criteria, in Proceedings of the 11th PErvasive Technologies Related to Assistive Environments Conference, pp. 319-326, 2018. DOI: 10.1145/3197768.3201566.

[13] Ostermeyer, E.; Danjou, C.; Durupt, A.; Le Duigou, J.. An ontology-based framework for the management of machining information in a data mining perspective. IFAC-PapersOnLine, vol.51, no.11, 302-307, 2018. DOI: 10.1016/j.ifacol.2018.08.300.

[14] Liu, D.; Liao, H.; Zio, E.; Miao, Q.; Zhang, B. Hu, C.; Azarian, M.H..: Complex System Health Management Based on Condition Monitoring and Test Data. IEEE Access, 6, 72028-72032, 2018.

[15] Yang, W.; Takakuwa, S. Simulation-based dynamic shop floor scheduling for a flexible manufacturing system in the industry 4.0 environment, in 2017 Winter Simulation Conference (WSC), pp. 3908-3916, 2017. DOI: 10.1109/WSC.2017.8248101.

[16] Akoka, J.; Comyn-Wattiau, I.; Laoufi, N. Research on Big Data-A systematic mapping study. Computer Standards \& Interfaces, 54, 105-115, 2017. DOI: 10.1016/j.csi.2017.01.004.

[17] Galletta, A.; Carnevale, L.; Celesti, A.; Fazio, M.; Villari, M. A cloud-based system for improving retention marketing loyalty programs in industry 4.0: a study on big data storage implications. IEEE Access, 6, 5485-5492, 2017. DOI: 10.1109/ACCESS.2017.2776400.

[18] Illa, P. K.; Padhi, N. Practical Guide to Smart Factory Transition Using IoT, Big Data and Edge Analytics. IEEE Access, 6, 55162-55170, 2018. DOI: 10.1109/ACCESS.2018.2872799.

[19] Li, X.; Li, D.; Li, S.; Wang, S.; Liu, C.. Exploiting Industrial Big Data Strategy for Load Balancing in Industrial Wireless Mobile Networks. IEEE Access, 6, 6644-6653, 2017. DOI: 10.1109/ACCESS.2017.2787978.

[20] Wan, J.; Hong, J.; Pang, Z.; Jayaraman, B.; Shen, F. Key technologies for smart factory of Industry 4.0. IEEE Access, 7, 17969-17974, 2017.

[21] Lopez, C. P.; Segura, M.; Santórum, M. Data Analytics and BI Framework based on Collective Intelligence and the Industry 4.0, in Proceedings of the 2019 2nd International Conference on Information Science and Systems, pp. 93-98, 2019. DOI: $10.1145 / 3322645.3322667$.
[22] Xu, X.; Hua, Q.. Industrial big data analysis in smart factory: Current status and research strategies. IEEE Access, 5, 17543-17551, 2017. DOI: 10.1109/ACCESS.2017.2741105

[23] Yan, H.; Wan, J.; Zhang, C.; Tang, S.; Hua, Q.; Wang, Z.. Industrial big data analytics for prediction of remaining useful life based on deep learning. IEEE Access, 6, 17190-17197, 2018. DOI: 10.1109/ACCESS.2018.2809681. 